\title{
Immune Checkpoint Inhibitor Therapy- Related Hypophysitis: A Case Report
}

\author{
Authors \\ Kreze A*, Roulová J, Klemperová K, Papp P1, Šíp O² \\ Internal Department Hospital Bulovka, Prague, Czech republic \\ ${ }^{1}$ Oncological Department Hospital Bulovka, Prague, Czech republic \\ ${ }^{2}$ Radiology Department Hospital Bulovka, Prague Czech republic \\ *Corresponding Author
}

Kreze A

\begin{abstract}
Hypophysitis due to programmed cell death protein-1 antibodies is not common. This condition may be life threating. Diagnosis remain clinical and laboratory. Treatment requires pituitary hormones replacement.

Keywords: Checkpoint inhibitors, Programmed cell death protein-1 inhibitor, Hypophysitis.
\end{abstract}

\section{Introduction}

Immune checkpoints inhibitors including pembrolizumab, are effective treatments for advanced neoplasias. Pembrolizumab are monoclonal antibodies directed at the programmed cell death 1 (PD-1) pathway and was subsequently also approved for the aditional treatment of renal carcinoma. Rare, but important adverse events include hypophysitis, requiring prompt diagosis and treatment.

\section{Case History}

A 67-year-old male was diagnosed with renal clear cell carcinoma of right kidney stage pT3aNOM0 and underwent exisional surgery. Two years later on whole-body computer tomography (CT) scan revealed metastases in the inferior lobe of the lung, bilateral hilar and mediastinal lymph node metastases in the C7 vertebrae, right humerus, both knees and ankles. The patient was started on anti PD-1 therapy with pebrozulimumab plus axitinib. After four months therapy, a CT showed a decreased size of pulmonary and lymph node metastases. About 5 months later, laboratory test showed THS 8.026 mU/1, (reference range: 3.350-4.940), fT4 10.9 pmol/l (reference range: 9-19), fT3 3.9 pmol/1 (reference range: $2.68-5.7$ ), consistent with postaxitinib hypothyroidism. After about 22 months of therapy, the patient presented to the hospital complaining of fatigue, nausea, vomitus, epigastric pain, diarrhoea. His laboratory test results were: $\mathrm{Na} 117 \mathrm{mmol} / \mathrm{l}$, eosinophils $2.6 \times 10^{9}$ /l (reference range: 0.0-0.5), cortisol $12.4 \mathrm{nmol} / \mathrm{l}$ (reference range: 263-724), ACTH $5.1 \mathrm{ng} / \mathrm{l}$ (reference range: 7.2-63.3), LH 0.5 U/1 (reference range: 1.7-8.6), FSH $1.7 \mathrm{U} / \mathrm{l}$ (reference range: 1.5-12.4), testosterone $0.44 \mathrm{nmol} / \mathrm{l}$ (reference range: 10.0-34.0), GH, IGFI,PRL were normal. An magnetic resonance imaging (MRI) (fig.1) brain scan showed an enlarged hypophysis $(10 \times 14 \times 16 \mathrm{~mm})$, heterogeneous enhancement 
with focal defects in T2-weighted images- figure 1. The diagnosis was grade 3 hypophysitis according to the CTCAE grading system (1). The patient was treated with dexamethasone $4 \mathrm{mg}$ (qd), initially intravenous, then definitively switched to
$20 \mathrm{mg}$ hydrocortisone daily and as previosly $75 \mathrm{ug}$ levothyroxine daily. Axitinib was stopped after diagnosis of hypothyreosis and pembrolizumab was later stopped too.

Figure 1: Hypophysitis on MRI

Sagittal and coronal sections of the pituitary. Sweling of the pituitary gland, thickening of the stalk with heterogenous enhancement signals

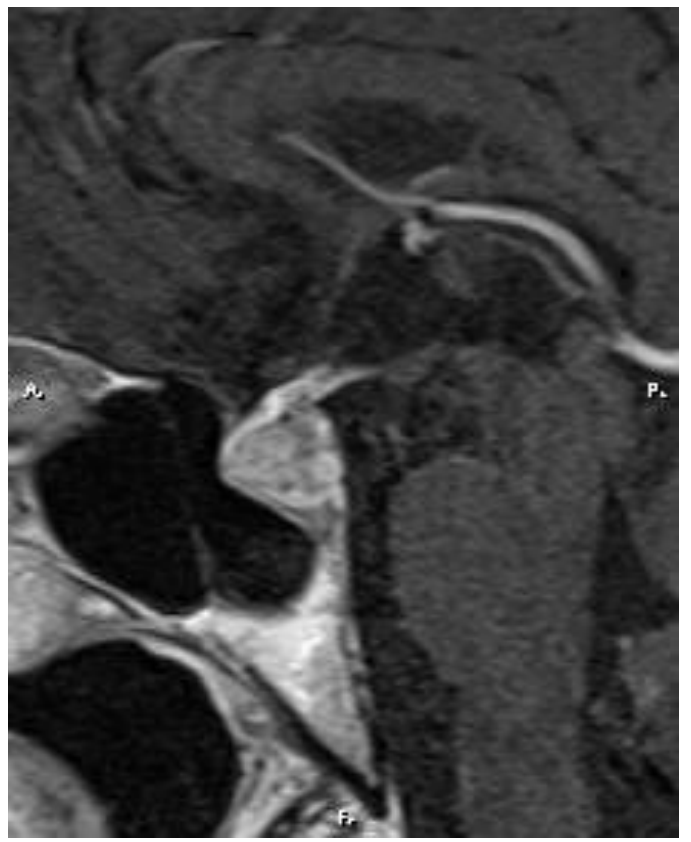

\section{Discussion}

As of May 2017 pembrolizumab is approved for indications: advanced melanoma, non-small lung cancer, Hodgkin's lymphoma, urothelial cancer, renal cell carcinoma, head and neck cancer, Merkel cell carcinoma and tumors of any origin with high microsatellite instability (Baxi et al.).

PD-1 is expressed on the surface of activated Tand B- lymphocytes and monocytes and is upregulated by tumor cells, helping them avoid the immune response. Checkponit inhibitors prevent this upregulation and allow the immune system to attack the cancer cell. Immune-mediated hypophysitis in relation to pembrolizumab is rare but important adverse event (0.2-1.2\% (GonzálezRodriguez et al.)). The precise mechanism by which immune checkpoint inhibitors cause hypophysitis remains unclear. The condition may be life threating because of adrenal insufficiency.

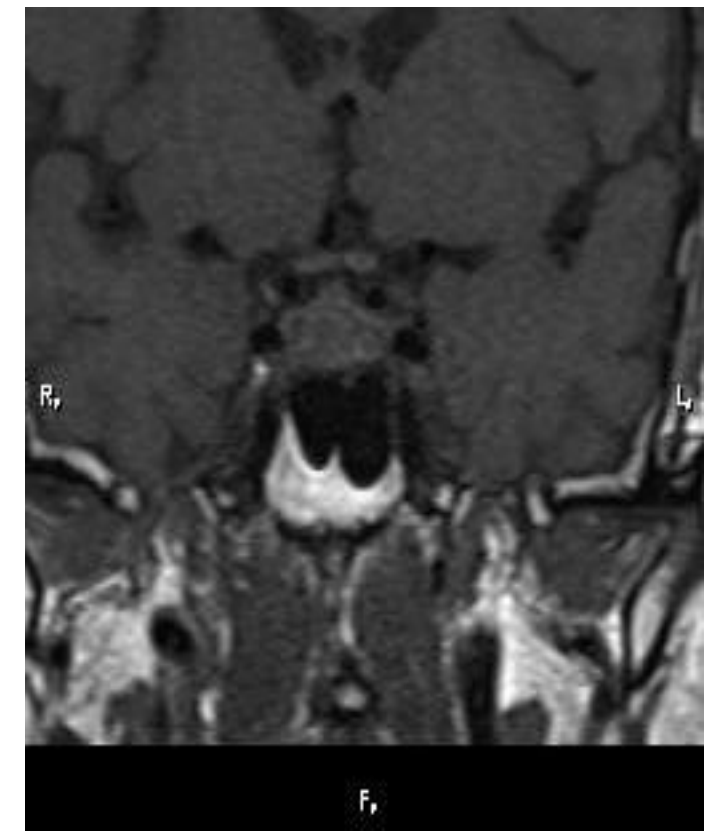

Diagnosis, after introducing pebrolizumab in treatment, is based on the clinical, laboratory and MRI picture, usually after 3.3-3.7 months of therapy (interval one day to 7.2 months) (Angelousi et al.). It requires prompt recognition and adequate management with hormone replacement (Lin et al.).

\section{Conclusion}

Immune checkpoint inhibitors are effective therapeutic modalities but, their use also has many adverse side effects affecting the endocrinne system. Therefore it is important to monitor any potential immune-mediated endocrinopathy while on PD-1 inhibitor therapy. To provide optimal care monitoring by an endocrinologis is recommended. 


\section{References}

1. U.S. Department Of Health And Human Services NioH, National Cancer Institute. Common Terminology Criteria for Adverse Events v4.0 (CTCAE) 2009; (updated june 14, 2010)

2. Baxi S, Yang A, Gennarelli RL, Khan N, Wang N, Boyce L, Korenstein D: Immunerelated adverse events for anti-PD-1 and PD-L1 drugs: systematic review and metaanalysis. BMJ 2018;360:k793 http://dxdoi.org/10.1136bmj.k793

3. González-Rodriguez E, GonzálezRodriguez D: Immune checkpoint inhibitors: review and management of endocrine adverse events. Oncologist 2016;21:7:804-816

4. Angelousi A, Chatzellis E, Kaltsas G: New molecular, biological, and Immunological agents inducing hypophysitis. Neuroendocrinology 2018;106:89-100

5. Lin $\mathrm{CH}$, Chen KH, Chen KY, Shih SR, Lu JY: Immune checkpoint inhibitor therapyinduced hypophysitis - a case series of Taiwanese patients. J Formos Med Assoc 2019; 118:1 Pt 3:524- 529. 